\title{
From the Industry Perspective of Chinese Game Industry Research in Quantitative Analysis
}

\author{
Na Wang*, Yongtao Zhou, Li Zhang \\ School of Business, Hubei University, Wuhan, China \\ Email: ${ }^{*}$ wn83067343@163.com
}

Received 21 February 2014; revised 10 March 2014; accepted 2 April 2014

Copyright (C) 2014 by authors and Scientific Research Publishing Inc.

This work is licensed under the Creative Commons Attribution International License (CC BY). http://creativecommons.org/licenses/by/4.0/

cc) (i) Open Access

\begin{abstract}
With Chinese Full-Text Database Journal Net, this paper makes a general analysis over the developing process and current situation of the game industry study which is undertaken with the view of the industry by China's scholars from 1979 to 2013. By means of content analysis approach, this paper takes extensive study covering research projects, topics, methods, theory applied and the shift of study topics.
\end{abstract}

\section{Keywords}

Game Industry, Full-Text Database CNKI, Journal Papers

\section{Introduction}

With the development and application of network technology in China, online game industry is also showing a rapid development trend. According to the 2012 China Game Industry Annual Conference, the China Game Industry Report 2012 showed that from the industrial scale in 2012, Chinese client network game users reached 140 million people, representing a growth rate of 12.5\%; website game users reached 271 million people, representing a growth rate of 33.4\%; mobile game users reached 0.89 million people, representing a growth rate of $73.7 \%$. Among them, pay online game users reached 8959.4 million with an increase of 35.1\%. From a view of practical revenue point, in 2012 actual sales revenue of China’s online game market was 602.8 billion yuan, representing a growth rate of $35.1 \%$, driven by the telecommunications, IT, media, advertising and other related industrial output value 63.12 billion yuan [1]. Meanwhile, many social scientists are increasingly concerned the study of the game industry. So far, what is the main thesis of academic research agenda for the game industry

*Corresponding author. 
from the perspective of industry in China? What are the main methods used? What are the industrial theories used? And how the pattern of change do research topics show? With the help of Chinese Full-Text Database Journal Net (CNKI), using content analysis, we analyzed the study of the process of the Chinese game industry and academic status quo.

In order to answer these questions, the paper is structured as follows: In the next section, we give our study design including the descriptions about sample and variables. In the subsequent section, results are described, this section includes the results about the research subjects, research topics, research methods, applied theory, and research model of development issues. The paper concludes with an outlook on future research and scientific and managerial implications.

\section{Organization of the Text}

\subsection{Study Design}

Currently popular online game has broad and narrow sense definitions. In a broad sense, the network game generally refers to one contacting between man and machine, man and man as well, while it is compared to out of network game under network environment. In a narrow sense, it refers to the online game based on TCP/IP protocol, relying in cyberspace, either a person or also multiplayer participates in the online game project at the same time [2]. In this article, online game mainly refers to narrowly network game, namely online game. To understand the current status quo of China's game industry research, the paper analyzed the game industry research papers being published in the period 1979-2013 from industry perspective.

\subsubsection{Sample}

In this paper, we use content analysis, and use "game industry" as the keyword in CNKI economic and management topics in June 2013, searching for all the research papers about the game industry between 1979 and 2013, we have gotten 1242 relevant papers. After carefully selected, we deleted 1129 papers which are not relevant with the research topics (industry perspective) and which they use game or industry just as a general industry terms which have been mentioned in the text, rather than as a literature of their research topics, at the last we got a valid sample actually obtained for the 113 papers, its distribution can be seen in Table 1 .

\subsubsection{Variables}

We take research papers as a research unit, the main study variables, including the research object of the paper, research issues, research methods, apply theory and development model of the papers' research issues.

\section{1) Research objects}

Objects of study in the paper are the main problems that the authors analyze, although the main body of this paper is to analyze the game industry, but according to the different entertainment devices, electronic games can be divided into different types. Thus based on the game industry the objects of our study is broken down as follows: the game industry, the online game industry, mobile game industry, computer game industry and its distribution can be seen in Table 2.

\section{2) Research issues}

Research topic is the main problem when the authors analyze the game industry concerned. By reading the papers repeatedly we first divided the papers into three levels, that are game industry development, game industry organization and game industry association, and then we divided them into 14 themes based on their main research questions, and their distributions can be seen in Table 3 .

\section{3) Research methods}

Research method is the main analytical methods in the analysis of related issues in the paper. We divided the research methods into two categories that are qualitative and quantitative methods. And the quantitative research method includes the questionnaire, laboratory analysis, secondary analysis, content analysis, empirical analysis, and the qualitative analysis includes overall analysis or presentation, comparative analysis, case study and literature review.

\section{4) Applied theory}

Applied theory refers to the use of theory in the analysis of related issues (such as SCP paradigm, Cournot model, etc.). And we classified each article based on whether the proposed research hypotheses or theories based on analysis of the problem. 
Table 1. Sample distribution.

\begin{tabular}{ccc}
\hline Year & Number of papers/articles & Weight $\%$ \\
\hline 2002 & 1 & 0.9 \\
2003 & 2 & 1.8 \\
2004 & 10 & 8.8 \\
2005 & 13 & 11.5 \\
2006 & 16 & 14.2 \\
2007 & 20 & 17.7 \\
2008 & 11 & 9.7 \\
2009 & 16 & 14.2 \\
2010 & 18 & 15.9 \\
2011 & 6 & 5.3 \\
Total & $\mathbf{1 1 3}$ & $\mathbf{1 0 0}$ \\
\hline
\end{tabular}

Source: Author arranged. The paper before 2002 was not relevant.

\section{Table 2. Distribution of study objects.}

\begin{tabular}{ccc}
\hline Objects of study & The number of study papers/articles & Weight\% \\
\hline Game industry & 10 & 8.8 \\
Online game industry & 93 & 82.3 \\
Mobile game industry & 8 & 7.09 \\
Computer game industry & 2 & 1.76 \\
Total & 113 & 100 \\
\hline
\end{tabular}

Source: Author arranged.

Table 3. Research topics and main contents.

\begin{tabular}{|c|c|c|}
\hline Research Levels & Research Topics & Research Contents \\
\hline $\begin{array}{l}\text { Development of } \\
\text { game industry }\end{array}$ & development motivation & the reasons for the rapid spread of the network industry \\
\hline \multirow[t]{4}{*}{53} & success factors & the reasons for the online game industry's success \\
\hline & $\begin{array}{l}\text { comparative analysis of South } \\
\text { Korea and Chinese Game industry }\end{array}$ & $\begin{array}{l}\text { comparative analysis for South Korea and Chinese Game industry } \\
\text { as a whole }\end{array}$ \\
\hline & status, trends and countermeasure & $\begin{array}{l}\text { the analysis of the game industry's overall status, trend forecasts and } \\
\text { countermeasures }\end{array}$ \\
\hline & industrial development strategy & SWOT analysis of online game industry and industry strategic choices \\
\hline $\begin{array}{l}\text { Organization of } \\
\text { game industry }\end{array}$ & market analysis & market size, structure, behavior and performance analysis of game industry \\
\hline \multirow[t]{7}{*}{59} & competitive environment & external competitive environment and countermeasure analysis of game industry \\
\hline & international trade & trade analysis of Chinese game industry and foreign game industry \\
\hline & industry management & how to supervise and support the game industry sector \\
\hline & industrial chain, value chain & $\begin{array}{l}\text { value chain or value chain integration and its analysis extension of } \\
\text { online game industry }\end{array}$ \\
\hline & business model & $\begin{array}{l}\text { business model and development and innovation analysis of online } \\
\text { game industry }\end{array}$ \\
\hline & competitiveness & $\begin{array}{c}\text { competitiveness of game industry and its comparative analysis } \\
\text { between home and abroad }\end{array}$ \\
\hline & analysis of consumer behavior & $\begin{array}{l}\text { analysis of consumer behavior patterns and game industry development } \\
\text { trend for game industry }\end{array}$ \\
\hline $\begin{array}{l}\text { Relevance of } \\
\text { game industry }\end{array}$ & $\begin{array}{l}\text { game industry and } \\
\text { related industries }\end{array}$ & interaction and development between game industry and related industries \\
\hline 1 & & \\
\hline
\end{tabular}

Source: Author arranged. 


\section{5) Development model of research topics}

Development model under study is the issue based on industry perspective, and focus on the process of change in game industry research. Analytical framework on this issue, we raised four-level division based on the research issues in the papers, namely the overall analysis of the game industry, external analysis of game industry, internal analysis of the game industry and related industries as well as between the internal analysis. By analyzing these four levels, we aim to identify research topics of development and change models.

\subsection{Results}

\subsubsection{Subjects}

In the research objects, the largest number of paper is online game industry (see Table 2), accounting for 82.3\% of the total number of valid papers, and only 10 papers take the entire game industry as the research object. The total number focus on game industry, computer game industry and the mobile phone game industry is 10 . Visibly, online game industry becomes the focus of academic attention to the game industry.

\subsubsection{Research Topics}

In the papers' topics, the most are the status of the game industry, research trends and countermeasures under the perspective in the 113 papers (see Table 4). And research contents focused on the overall status of the game industry, trend forecasts and countermeasures. The second is the market analysis of the game industry, the main research contents include market size, market structure, market behavior and market performance.

According to statistics, we can find that the Chinese industry perspective of academic research in the game industry focused on the game industry status, trends and countermeasures, the game industry market analysis, as well as game industry business model, industrial chain, industrial competitiveness and so on. Especially for the game industry status, trends and countermeasures analysis, they are still an issue of concern to most domestic scholars. For the study of the industry's business model, the industrial chain, industrial competitiveness, the competitive environment and other issues, although there are some in volume terms, but they are limited to a general description and analysis, so we can see the lack of in-depth empirical analysis of the game depth study of the industry to be further expanded.

\subsubsection{Research Methods}

In research methods, qualitative research has a total number of papers representing the number of samples collected. In all 113 papers, a non-quantitative research method is used in 107 papers, accounting for $94.7 \%$ of all papers. This has a lack of a clear majority of papers on research methods but they give only game industry analysis or a general description of such papers reaching 96 , accounting for $84.9 \%$ of all papers. In comparison, the number of game industries quantitative research papers is 6 , accounting for $5.3 \%$ (see Table 5).

Table 4. Distribution of research topics.

\begin{tabular}{|c|c|c|}
\hline Research topics & The number of study papers/articles & Weight\% \\
\hline Status development trend and countermeasures & 50 & 44.2 \\
\hline Market analysis & 10 & 8.8 \\
\hline Business model & 17 & 15 \\
\hline Industry chain value chain & 14 & 12.4 \\
\hline Industry strategy & 10 & 8.8 \\
\hline Competitiveness & 5 & 4.4 \\
\hline Comparative analysis of game industry between Chinese and South Korea & 5 & 4.4 \\
\hline Success factors & 1 & 0.9 \\
\hline Industry management & 3 & 2.7 \\
\hline Develop motivations & 2 & 1.8 \\
\hline Competitive environment & 2 & 1.8 \\
\hline Consumer behavior & 4 & 3.5 \\
\hline Pricing & 1 & 0.9 \\
\hline Economic analysis & 2 & 1.8 \\
\hline Enterprise analysis & 1 & 0.9 \\
\hline
\end{tabular}

Source: Author arranged. For some of the papers involve more than one issue, so the cumulative effective number is 127 , and the percentage is more than $100 \%$. 
Table 5. Distribution of research methods.

\begin{tabular}{ccc}
\hline Research methods & Number of/papers & Weights\% \\
\hline Qualitative methods & 107 & 94.7 \\
General analysis or presentation & 96 & 84.9 \\
Comparative analysis & 5 & 4.4 \\
Literature review & 1 & 0.8 \\
Case study & 5 & 4.4 \\
Quantitative methods & 6 & 5.3 \\
Empirical analysis & 6 & 5.3 \\
Total & 113 & 100.0 \\
\hline
\end{tabular}

Source: Author arranged.

\subsubsection{Applied Theory}

Looking at the current research on the Chinese game industry under industry perspective, there are three basic findings.

1) Lack of support from the vast majority of theoretical papers, resulting in insufficient depth study.

In all the papers, the number of paper which mentioned certain economic management theory and based on the theory putting forward specific research frameworks and conclusions is only 23, accounting for $26.4 \%$. From the publishing time, the paper using game theory related industries first appeared in 2004, but the number of paper is only 2. Visibly, although some papers used some kind of theories, but the theories didn't base on this perspective issues that related to the game industry in-depth empirical research, and they stay in the game industry, according to some theories' general descriptions.

2) Theory applied is more complex, they are more focused on theoretical perspective.

In all the papers mentioned, the industrial chain theory was used largest, there are seven papers related to this theory; There have two theories used three times, the theories are SCP paradigm used in industry market analysis and SWOT during competition analysis. And the theories used two times are value chain theory and Porter's competition theory (including the national competition diamond model and three basic models of competitive strategies); the rest theories such as outsourcing, monopolistic competition, Cournot model, hierarchy of needs, market structure theory and input-output theory are used once.

3) For the theoretical analysis papers, the research deep is not enough, and the concepts are confused.

In the 23 papers which apply the theory to analyze, such as "sustainable development”, “core competencies” and so on, but the application of theory only stay on the surface, and they are just being used on a general description of the analysis level. And the essence of these concepts are been borrowed and they did not been applied to the relevant theory, there are more papers confusing the concept of industry chain and value chain's position. Based on the Porter's theory of competitive advantage, the original object of the value chain is the definition between the various activities within the enterprise, which is the internal chain between creating value for customers.

\subsubsection{Research Model of Development Issues}

In this paper, we based on the overall analysis of the game industry, game industry external analysis, internal analysis of the game industry and game industry analysis related industries these four levels to examine the development of the industrial perspective of the game model, industry research issues.

From time variation the number of papers published can be seen on the overall status of the game industry trends' analysis is always the focus of academic attention, accounting for $46.9 \%$ of all samples. Beginning from 2004, there have been studies on the organization of the game industry analysis, such as the industrial chain and profit model, this kind of paper made up 52.2\% of the total. From 2008 there appeared analysis of game industry associated with related industries, such paper only account $0.9 \%$ of the total.

Visibly, 2002-2003 is the exploration of academic research stage of the game industry in China, 2004-2011 is the full swing phase for research about game industry organization. The scope of its research ranging from the development of game industry gradually extended to the internal of game industry and the game industry within the organization and related industries, but in the view of overall points, the academic study of the game industry is still in infancy in China, which can be seen in Table 6. 
Table 6. Research topics of the development model.

\begin{tabular}{ccccc}
\hline Year & Industry development & Industrial organization & Related industries & Total \\
\hline 2002 & 1 & 0 & 0 & 1 \\
2003 & 2 & 0 & 0 & 2 \\
2004 & 5 & 5 & 0 & 10 \\
2005 & 5 & 8 & 0 & 13 \\
2006 & 10 & 6 & 0 & 16 \\
2007 & 7 & 13 & 0 & 20 \\
2008 & 6 & 4 & 1 & 11 \\
2009 & 6 & 10 & 0 & 16 \\
2010 & 9 & 9 & 0 & 18 \\
2011 & 2 & 4 & 0 & 1 \\
Total & 53 & 59 & 1 & 6 \\
\hline
\end{tabular}

Source: Author arranged.

\subsection{Conclusions}

Through the perspective of the Chinese industry circles in the above study on the status of the game industry analysis, the following basic conclusions can be drawn.

In the research content, academic study of the Chinese game industry, focused on the current state of the game industry, trends and countermeasures, and most of the papers are remaining in the general description and analysis of the game industry relative issues. Compared to the same period of the game industry abroad, there are significant differences. Overall, the academic research topics of the game industry in China remain to be further expanded. We also need to further deepen the research fields.

In research methods, the current academic research on game industry in China mainly used qualitative research method. Although, in recent years, many papers in the research and analysis mentioned a lot of relevant data, but most of these data are based on research findings related to the company and they are just a direct reference, lacking relevant statistical data analysis, thus we put such papers to qualitative research category. There are a few quantitative researches, and the researches lack depth. While in the theory use, most papers lack appropriate theoretical supports and discussions of theories, even if the use of theoretical papers has remained mostly being scattered in the use of the theories, or even just a simple theoretical concepts related borrowing, and the former theory is not clearly defined, they confused the use of the theories and conceptions. Meanwhile, different scholars have not been able to form a more coherent theory of vision, and there is a lack of theoretical and empirical research, especially between the combinations of quantitative researches.

\section{Literature References}

Here's network environment, including access to wired and wireless LAN, WAN, Internet, including not only common networked PC games, but also networked console (console) games and wireless games (mobile games).

\section{Acknowledgements}

This research was financially supported by the Ministry of Education Humanities and Social Sciences Research Project (Grant No. 13YJC630169) and Hubei Provincial Department of Education Humanities and Social Sciences guiding project (bilateral platform for enterprise business model-taking video game platform, for example).

\section{References}

[1] Chinese Version of the Game Work Association, International Data Corporation (2012) China Game Industry Report Summary. China Renmin University Press, Beijing.

[2] Yang, F. (2007) Review of the Online Game Industry Research. Financial Services Sector, 5, 9-13. 
Scientific Research Publishing (SCIRP) is one of the largest Open Access journal publishers. It is currently publishing more than 200 open access, online, peer-reviewed journals covering a wide range of academic disciplines. SCIRP serves the worldwide academic communities and contributes to the progress and application of science with its publication.

Other selected journals from SCIRP are listed as below. Submit your manuscript to us via either submit@scirp.org or Online Submission Portal.
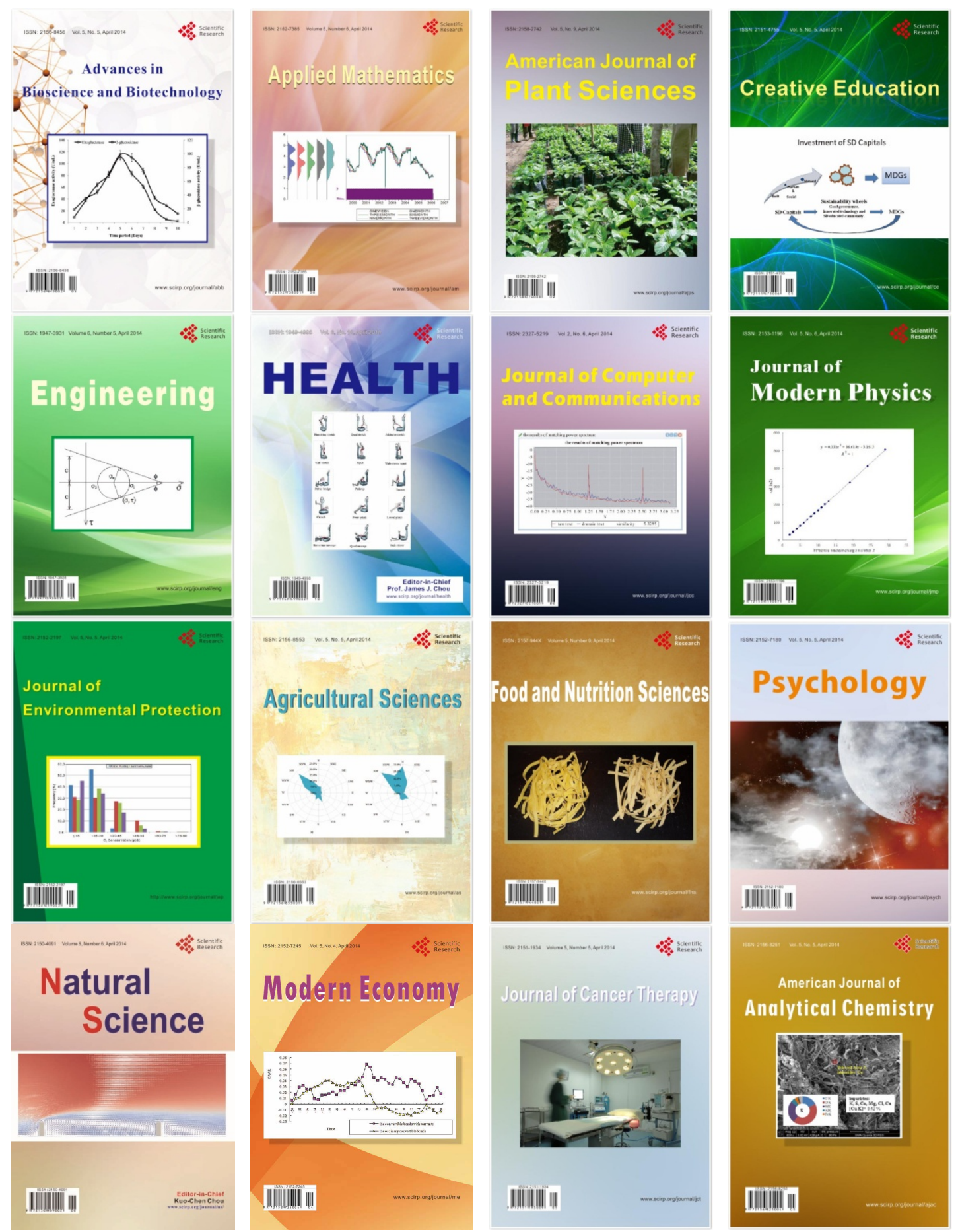